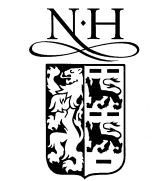

ELSEVIER

\title{
Wire drawing conducted in the R-phase of TiNi shape memory alloys
}

\author{
S.K. Wu ${ }^{\mathrm{a}, *}$, H.C. Lin ${ }^{\mathrm{b}}$, Y.C. Yen ${ }^{\mathrm{a}}$, J.C. Chen ${ }^{\mathrm{a}}$ \\ a Institute of Materials Science and Engineering, National Taiwan University, Taipei 106, Taiwan \\ ${ }^{\mathrm{b}}$ Department of Materials Science, Feng Chia University, Taichung 407, Taiwan
}

Received 7 January 2000; received in revised form 17 May 2000; accepted 18 May 2000

\begin{abstract}
The wire drawing conducted in the R-phase of TiNi shape memory alloys shows that the drawing stress in the R-phase is lower than that in the parent B2 phase and B19' martensite. This feature is ascribed to the R-phase having lower shear modulus. The martensite can be stress-induced by cold drawing in the R-phase. The cold drawing and subsequent annealing conducted in the R-phase can significantly affect the transformation temperatures and transformation heats of the drawn wires. (C) 2000 Elsevier Science B.V. All rights reserved.
\end{abstract}

Keywords: TiNi shape memory alloys; R-phase; Wire drawing; Stress-induced martensite in R-phase; Transformation temperature and heat; Drawing stress

\section{Introduction}

TiNi alloys are an important class of shape memory alloys (SMAs). They exhibit not only the shape memory effect (SME) [1], but also unusual superelasticity (SE) [2,3] and high damping capacities [4,5]. These properties, along with their superior ductility, strength, fatigue and corrosion resistance, have resulted in many applications of TiNi SMAs, in which the use of TiNi wire is dominant. In wire applications, TiNi SMAs are usually produced as wire springs, hollow wires or various nonregular shapes [6-9]. Recently, ultra-fine or hollow TiNi wires have been developed and have shown improved SME,

\footnotetext{
* Corresponding author. Tel.: +886-2-363-0231; fax: +886-22363-4562.

E-mail address: skw@ccms.ntu.edu.tw (S.K. Wu).
}

which is enhanced by their high cooling rates during the cooling process. There are many promising applications for these wires in products like microactuators and microsprings. Therefore, the understanding of drawn wire properties is important for TiNi SMA's applications.

As mentioned above, TiNi wire products have many potential applications. The roadblocks to their development, however, are caused by difficulties in the manufacturing process. It is well known that TiNi alloys can be tensile-deformed in a ductile manner to more than $50 \%$ strain prior to fracture [1]. But severe strain hardening, accompanied by coldworking and wire-drawing, hinders their workability. To overcome this difficulty, some special wire drawing processes have been developed, such as dieless drawing [10] and clad-chip extrusion [11]. However, these new processes still have some technical limits 
[10,11]. As we approach a solution to these problems, an understanding of the intrinsic wire drawing properties of TiNi SMAs becomes important. In a previous paper [12], we have studied the wire drawing of TiNi SMAs conducted in their parent B2 phase and B19' martensite. The wire drawing at around the Ms temperature of TiNi SMAs is recommended. Meanwhile, it has been found that wire drawing conducted in the parent B2 phase is much more difficult than in the martensite, because the drawn wire will spring back due to its superelastic behavior. Therefore, to successfully perform the wire drawing of the parent B2 phase of TiNi SMAs, TiNi alloys should be first immersed in a cooling medium to transform to the martensite. This process is troublesome and inefficient.

As well as the parent B2 phase and B19' martensite, TiNi SMAs can exhibit the R-phase at room temperature under the following conditions:

1. The introduction of rearranged dislocations which are produced by thermal cycling $[13,14]$ or coldworking and then annealing at low temperatures $[15,16]$.

2. The introduction of precipitates by heat treatment at temperatures between $300^{\circ} \mathrm{C}$ and $500^{\circ} \mathrm{C}$ for the Ni-rich alloys [17-19].

3. The addition of certain third elements that suppress martensitic transformation temperatures [20].

The B2 $\leftrightarrow$ R-phase of TiNi alloys exhibits the thermoelastic behaviors as the B2 $\leftrightarrow$ B19' martensite [17]. It is expected that the R-phase has similar drawing properties as the $\mathrm{B} 19^{\prime}$ martensite. Hence, it is important and valuable to understand the wiredrawing properties of the R-phase. The aim of this study is to investigate the wire-drawing properties of TiNi SMAs conducted in their R-phase. At the same time, the transformation behavior of TiNi wires with various degrees of cold drawing conducted in the $\mathrm{R}$-phase is also discussed.

\section{Experimental procedure}

The conventional tungsten arc-melting technique was employed to prepare the $\mathrm{Ti}_{50} \mathrm{Ni}_{50}, \mathrm{Ti}_{49.7} \mathrm{Ni}_{50.3}$ and $\mathrm{Ti}_{49} \mathrm{Ni}_{51}$ (all in at.\%) SMAs. Titanium (purity:
99.7 wt.\%) and nickel (purity: 99.8 wt.\%), totaling about $150 \mathrm{~g}$, were melted and remelted at least six times in an argon atmosphere. The weight loss during melting was negligible. The as-melted buttons were homogenized at $1050^{\circ} \mathrm{C}$ for $72 \mathrm{~h}$ and then hot-rolled at $850^{\circ} \mathrm{C}$ to plates with $1.25-\mathrm{mm}$ thickness. Specimens for the wire drawing $(1.2 \mathrm{~mm} \varnothing \times$ $300 \mathrm{~mm}$ ) were carefully prepared from these plates. These specimens were vacuum-sealed in quartz tubes, annealed at $800^{\circ} \mathrm{C}$ for $2 \mathrm{~h}$ and then quenched in water. In order to obtain the R-phase at room temperature (R-phase-treated specimens), the $\mathrm{Ti}_{50} \mathrm{Ni}_{50}$ and $\mathrm{Ti}_{49.7} \mathrm{Ni}_{50.3}$ alloys were subjected to a $25 \%$ cold drawing and then $500^{\circ} \mathrm{C} \times 30 \mathrm{~min}$ annealing, and the $\mathrm{Ti}_{49} \mathrm{Ni}_{51}$ alloy was subjected to a $400^{\circ} \mathrm{C} \times 20 \mathrm{~h}$ aging.

The drawing machine and the wire head machine have been illustrated in our previous paper [12]. A drawing die of tungsten carbide was used in this study. The drawing process can be conducted under the controlled speed of $5-20 \mathrm{~m} / \mathrm{min}$ and the drawing force can be recorded in situ by an S-type Load Cell. The transformation behavior was studied by using differential scanning calorimetry (DSC) measurement. A Du Pont 9900 thermal analyzer equipped with a quantitative scanning system 910 DSC cell was used to control the heating/cooling rate on samples encapsulated in an aluminum pan. Temperatures were ranged from $-20^{\circ} \mathrm{C}$ to $+140^{\circ} \mathrm{C}$ with a heating/cooling rate of $10^{\circ} \mathrm{C} / \mathrm{min}$. The heat of transformation, $\Delta H$, from the area under the DSC peak was automatically calculated using the equipment software packages. The XRD analysis was carried out at room temperature with the Philips PW1710 X-ray diffractometer under the conditions of $\mathrm{Cu} \mathrm{K} \alpha$ radiation, $30 \mathrm{kV}$ tube voltage, and $20 \mathrm{~mA}$ current.

\section{Results and discussion}

Fig. 1(a-c) shows the experimental results of DSC measurements for three R-phase-treated TiNi alloys: $\mathrm{A}-\mathrm{Ti}_{50} \mathrm{Ni}_{50}, \mathrm{~B}-\mathrm{Ti}_{49.7} \mathrm{Ni}_{50.3}$ and $\mathrm{C}-$ $\mathrm{Ti}_{49} \mathrm{Ni}_{51}$. The two separated peaks in the cooling cycle indicate that the R-phase transformation can appear prior to the martensitic transformation for these alloys. Obviously, these R-phase-treated TiNi 

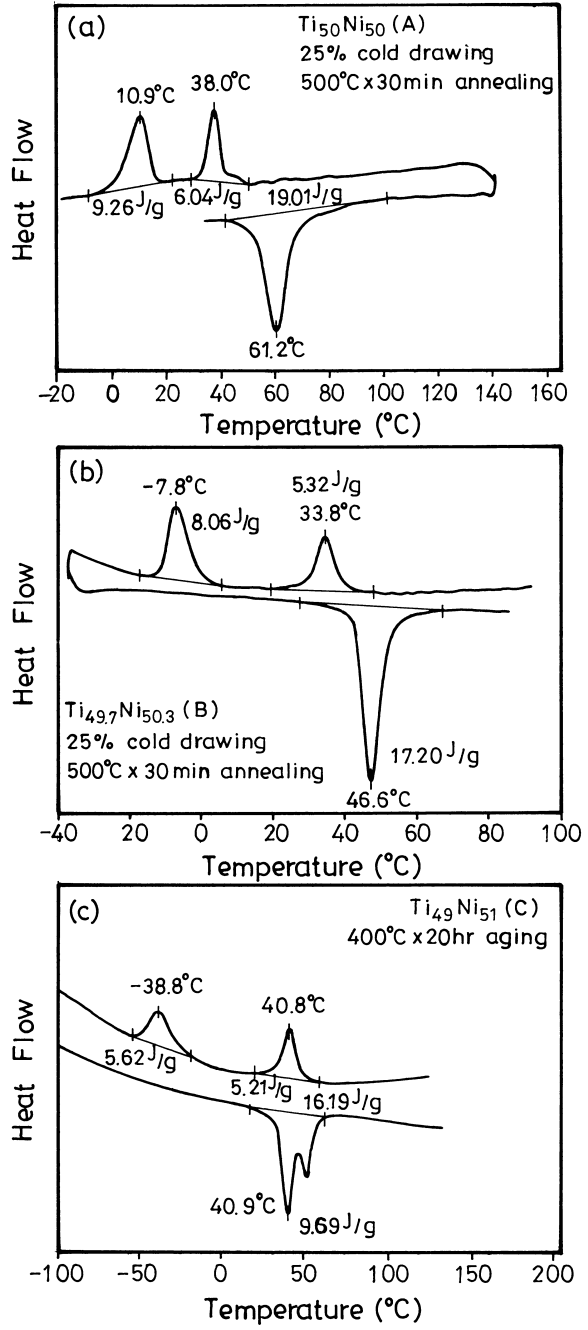

Fig. 1. DSC curves for the R-phase-treated TiNi alloys: (a) $\mathrm{Ti}_{50} \mathrm{Ni}_{50}$ (A) alloy; (b) $\mathrm{Ti}_{49.7} \mathrm{Ni}_{50.3}$ (B) alloy; (c) $\mathrm{Ti}_{49} \mathrm{Ni}_{51}$ (C) alloy.

alloys exhibit the stable R-phase at around room temperature during cooling. The existence of R-phase for these alloys can also be observed from the XRD measurements. Fig. 2(a,b) shows the XRD patterns measured at room temperature for the $\mathrm{R}$-phase-treated alloys $\mathrm{Ti}_{50} \mathrm{Ni}_{50}(\mathrm{~A})$ and $\mathrm{Ti}_{49} \mathrm{Ni}_{51}(\mathrm{C})$, respectively. The typical XRD spectra of the R-phase of TiNi SMAs, but not the parent B2 phase or B19' martensite, are observed in Fig. 2(a,b).

In Fig. 3, curves $\mathrm{A}, \mathrm{B}$ and $\mathrm{C}$ show the drawing stress vs. drawing temperature for these R-phase-
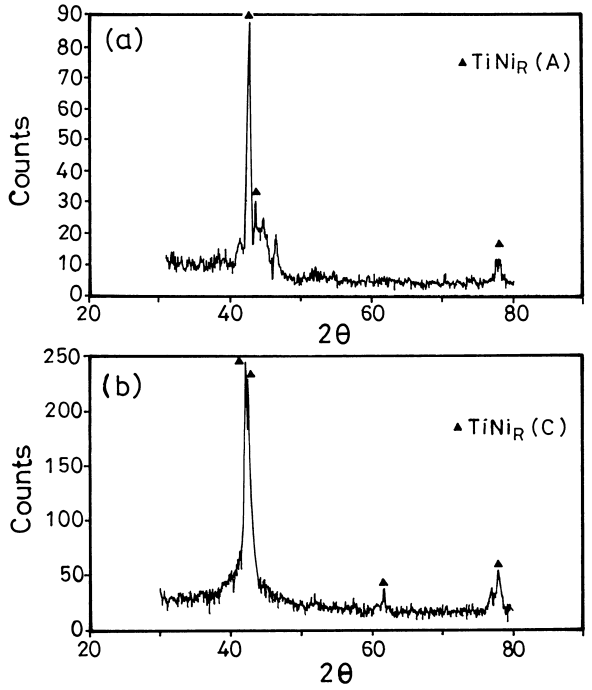

Fig. 2. XRD patterns measured at room temperature for the R-phase-treated TiNi alloys: (a) $\mathrm{Ti}_{50} \mathrm{Ni}_{50}$ (A) alloy; (b) $\mathrm{Ti}_{49.7} \mathrm{Ni}_{50.3}(\mathrm{~B})$ alloy.

treated alloys $-\mathrm{Ti}_{50} \mathrm{Ni}_{50}(\mathrm{~A}), \mathrm{Ti}_{49.7} \mathrm{Ni}_{50.3}(\mathrm{~B})$ and $\mathrm{Ti}_{49} \mathrm{Ni}_{51}(\mathrm{C})$, respectively. Here, the drawing stress is defined as the drawing force divided by the wire cross-section area. As can be seen in Fig. 3, for all these TiNi alloys, the drawing stress in the R-phase is mostly lower than that in the parent B2 phase and the B19' martensite. The lower shear modulus of R-phase than those of B2 phase and B19' martensite, as found in the internal friction measurement [19], is responsible for its lower drawing stress. The lower the shear modulus, the easier the plastic deformation and hence the lower the drawing stress. With careful

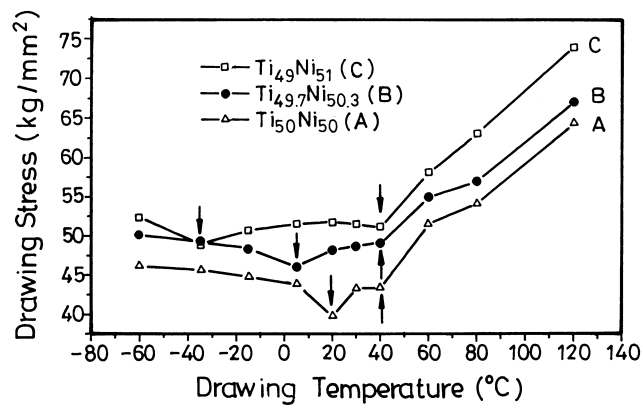

Fig. 3. The drawing stress vs. drawing temperature for the Rphase-treated TiNi alloys: (a) $\mathrm{Ti}_{50} \mathrm{Ni}_{50}$ (A) alloy; (b) $\mathrm{Ti}_{49.7} \mathrm{Ni}_{50.3}$ (B) alloy; (c) $\mathrm{Ti}_{49} \mathrm{Ni}_{51}$ (C) alloy. 


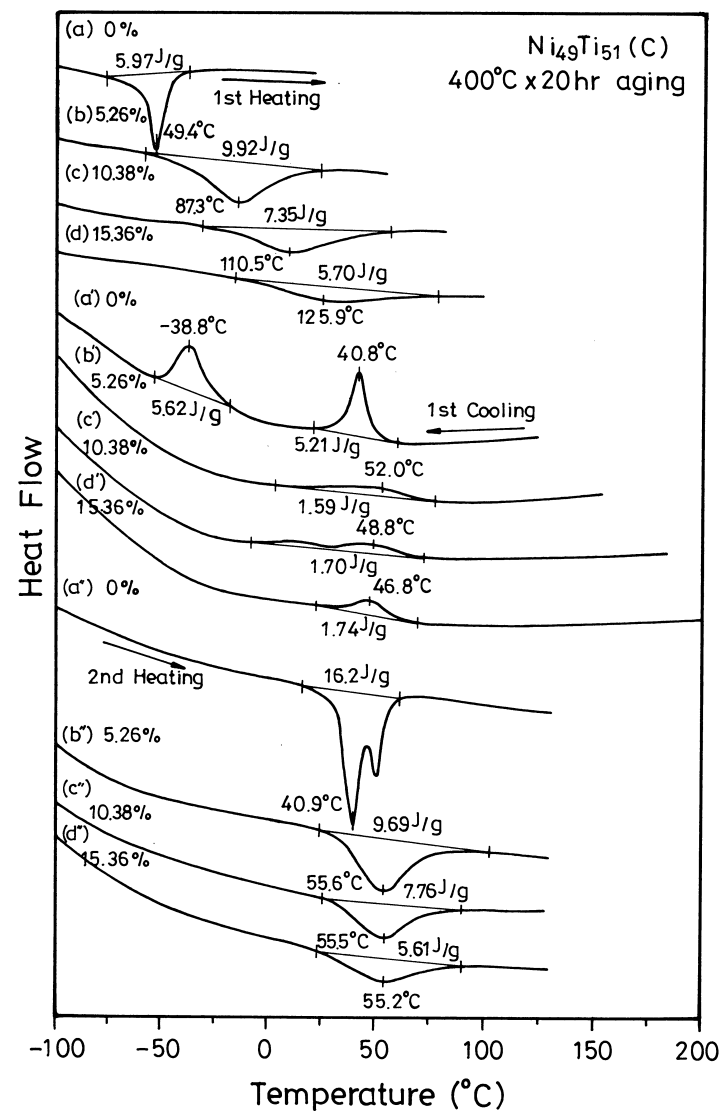

Fig. 4. DSC curves of the first heating cycle, the subsequent cooling and the second heating cycle, respectively, for the $400^{\circ} \mathrm{C}$ $\times 20 \mathrm{~h}$ aged $\mathrm{Ti}_{49} \mathrm{Ni}_{51}(\mathrm{C})$ alloy specimens with various degrees of cold drawing conducted in the R-phase.

examination of $\mathrm{A}, \mathrm{B}$ and $\mathrm{C}$ curves in Fig. 3, we find that the drawing stress minima occur at around the range of $\mathrm{R} \rightarrow \mathrm{M}$ transformation temperatures, as indicated by the arrows. Besides, the drawing stress around the $\mathrm{B} 2 \rightarrow \mathrm{R}$ transformation temperature is lower than that of $\mathrm{B} 2$ phase. These features implicate that the $\mathrm{B} 2 \rightarrow \mathrm{R}$ and $\mathrm{R} \rightarrow \mathrm{M}$ transformations are related to the phenomenon of "lattice softening", a behavior that is similar to the $\mathrm{B} 2 \rightarrow \mathrm{M}$ transformation, which occurs as a "soft" mode in a particular crystallographic orientation [21,22].

Fig. 4(a-d), $\left(a^{\prime}-d^{\prime}\right),\left(a^{\prime \prime}-d^{\prime \prime}\right)$ shows the DSC curves of the first heating cycle, the subsequent cooling cycle and then the second heating cycle, respectively, for the $400^{\circ} \mathrm{C} \times 20 \mathrm{~h}$ aged $\mathrm{Ti}_{49} \mathrm{Ni}_{51}(\mathrm{C})$ specimens with various degrees of cold drawing con- ducted in the R-phase. In Fig. 4, some important features are described as follows.

(1) The reverse transformation temperature of the first heating cycle (Fig. 4(a-d)) is found to increase with an increasing degree of cold drawing. The $\Delta H$ value of DSC peak in the first heating cycle for the $5.26 \%$ cold-drawn specimen is much higher (9.92 $\mathrm{J} / \mathrm{g})$ than that of the as-aged one $(5.97 \mathrm{~J} / \mathrm{g})$, but it gradually decreases when the degree of cold drawing is increased.

(2) The $\Delta H$ values of the $\mathrm{B} 2 \rightarrow \mathrm{R}$ transformation in the subsequent cooling cycle (Fig. $4\left(\mathrm{a}^{\prime}-\mathrm{d}^{\prime}\right)$ ) for the cold-drawn specimens are quite small $(\approx 1.70 \mathrm{~J} / \mathrm{g})$ when compared to that of the as-aged one $(\approx 5.21$ $\mathrm{J} / \mathrm{g}$ ). Meanwhile, the $\mathrm{R} \rightarrow \mathrm{M}$ transformation is depressed by cold drawing and there is no obvious DSC peak in the measured temperature range, though partial $\mathrm{R} \rightarrow \mathrm{M}$ transformation may occur.

(3) The reverse transformation temperature in the second heating cycle (Fig. $\left.4\left(\mathrm{a}^{\prime \prime}-\mathrm{d}^{\prime \prime}\right)\right)$ appears at a lower temperature than that in the first heating cycle, and the associated $\Delta H$ value decreases as the degree of cold drawing is increased.

These phenomena can be explained as follows: Fig. 5 shows the XRD pattern measured at room temperature for the aged $\mathrm{Ti}_{49} \mathrm{Ni}_{51}(\mathrm{C})$ specimen subjected to a $10.38 \%$ cold drawing at room temperature. As well as the R-phase, some martensite spectra appear in Fig. 5. This indicates that the $\mathrm{R} \rightarrow \mathrm{M}$ transformation can be stress-induced by cold drawing in the R-phase, a behavior that is similar to the stress-induced $\mathrm{B} 2 \rightarrow \mathrm{M}$ martensite in the $\mathrm{B} 2$ phase. The R-phase-treated $\mathrm{Ti}_{49} \mathrm{Ni}_{51}$ alloy has been reported to have the stress induced $\mathrm{R} \rightarrow \mathrm{B} 2$ transfor-

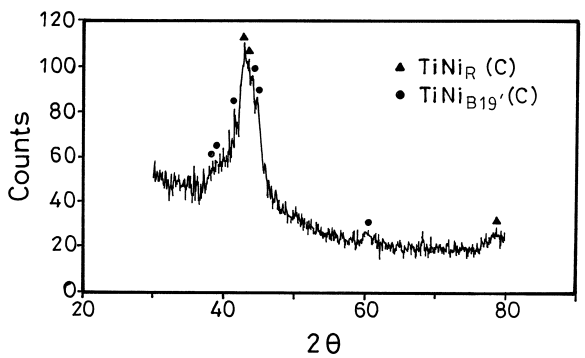

Fig. 5. The XRD pattern measured at room temperature for the aged $\mathrm{Ti}_{49} \mathrm{Ni}_{51}(\mathrm{C})$ alloy specimen subjected to $10.38 \%$ cold drawing in the R-phase. 
mation under an applied stress [23]. Therefore, the result of Fig. 5 may also come from the stress induced $\mathrm{R} \rightarrow \mathrm{B} 2$ and then stress induced $\mathrm{B} 2 \rightarrow \mathrm{M}$ serial transformations. This causes that the $\mathrm{M} \rightarrow \mathrm{B} 2$ and $\mathrm{R} \rightarrow \mathrm{B} 2$ transformational $\Delta H$ values of Fig. $4(\mathrm{~b}, \mathrm{c})$ during the first heating cycle are higher than that of as-aged specimen of Fig. 4(a) in which the $\Delta H$ value only associates with the $\mathrm{R} \rightarrow \mathrm{B} 2$ transformation. However, during the cold-drawing process, lots of deformed structures and defects are introduced. These deformed structures and defects can stabilize the R-phase and the martensite [24], hence, the reverse transformation temperature of the first heat cycle (Fig. 4(b-d)) shifts to a higher one. The more the degree of cold drawing, the higher the reverse transformation temperature. In the same way, the decrement of transformational $\Delta H$ value for the specimens with the degree of cold drawing $\geqq 5.26 \%$ (Fig. 4(b-d)) is also closely related to these deformed structures and defects [25].

After the first reverse transformation, the stabilization of R-phase and stress-induced martensite dies out and the subsequent martensitic transformation temperature is depressed by the retained dislocations, as shown in Fig. 4( $\left.b^{\prime}-d^{\prime}\right)$ [24]. The amount of retained dislocations should be proportional to the degree of cold drawing. The higher the dislocations retained in the cold-drawn specimens, the lower the martensitic transformation temperature they have. Therefore, in the measuring temperature range (down to $-100^{\circ} \mathrm{C}$ ), less $\mathrm{R}$-phase is transformed to the martensite for the specimen with higher degree of cold drawing because its martensitic transformation is more depressed. This phenomenon can also be responsible for the smaller transformational $\Delta H$ value in the second heating cycle (Fig. $\left.4\left(b^{\prime \prime}-d^{\prime \prime}\right)\right)$ for those specimens with severe cold drawing. Meanwhile, because of the die-out of the R-phase stabilization, the $\mathrm{R} \rightarrow \mathrm{B} 2$ transtemperature in the second heating cycle recovers to a lower temperature than that occurred in the first heating cycle.

It is also well known that the R-phase transformation can be assisted by the coherent stress around the coherent boundaries between the matrix and the $\mathrm{Ti}_{11} \mathrm{Ni}_{14}$ precipitates [26]. However, these coherent boundaries can be partially destroyed by cold drawing. Hence, the transformable volume of $\mathrm{B} 2 \rightarrow \mathrm{R}$ during the cooling process should be decreased and the associated $\Delta H$ value is also decreased for the cold-drawn specimen, as shown in Fig. $4\left(b^{\prime}-d^{\prime}\right)$.

\section{Conclusions}

1. The drawing stress of TiNi wire drawing in the $\mathrm{R}$-phase is lower than that in the parent B2 phase and $\mathrm{B} 19^{\prime}$ martensite. This feature is ascribed to the lower shear modulus of the R-phase. The drawing stress minima appear around the transformation temperatures of $\mathrm{B} 2 \rightarrow \mathrm{R}$ and $\mathrm{R} \rightarrow \mathrm{M}$ transformations.

2. The stress-induced $\mathrm{R} \rightarrow \mathrm{M}$ transformation can occur at TiNi SMAs cold-drawn in the R-phase. This behavior is similar to the stress-induced $\mathrm{B} 2 \rightarrow \mathrm{M}$ transformation observed in the B2 phase. The martensite observed in the cold-drawn R-phase wire may also come from the stress-induced $\mathrm{R} \rightarrow \mathrm{B} 2$ and then stress-induced $\mathrm{B} 2 \rightarrow \mathrm{M}$ serial transformations.

3. The cold drawing and the subsequent annealing conducted in the R-phase introduce and then annihilate the deformed structures and defects and can significantly affect the transformation temperatures and transformation heats of the drawn wires.

\section{Acknowledgements}

The authors are pleased to acknowledge the financial support of this research by the Tjing Ling Research Institute, National Taiwan University, under Grants No. 82-G-10 and 83-G-10, and by National Science Council (NSC), Republic of China, under Grant NSC83-0405-E002-011.

\section{References}

[1] S. Miyazaki, K. Otsuka, Y. Suzuki, Scr. Metall. 15 (1981) 287-292.

[2] S. Miyazaki, Y. Ohmi, K. Otsuka, Y. Suzuki, ICOMAT-82, J. Phys. 43 (1982) C4255-C4260.

[3] S. Miyazaki, T. Imai, Y. Igo, K. Otsuka, Metall. Trans. A 17 (1986) 115-120.

[4] H.C. Lin, S.K. Wu, M.T. Yeh, Metall. Trans. A 24 (1993) 2189-2194.

[5] H.C. Lin, S.K. Wu, Y.C. Chang, Metall. Trans. A 26 (1995) $851-858$.

[6] C.M. Jackson, H.J. Wagner, R.J. Wasilewski, NASA [Spec. Publ.] SP 5110 (1972) 19-21. 
[7] W.J. Buehler, W.B. Cross, Wire J. Int. 2 (1969) 41-49.

[8] M. Aiba, H. Nagai, M. Asakawa, Mater. Jpn., JIM 31 (1992) 541-543 (In Japanese).

[9] K. Yoshida, H. Tanaka, Wire 45 (1995) 89-94.

[10] Y. Kawaguchi, K. Katsube, M. Murahasi, Y. Yamada, Wire J. Int. 12 (1991) 53-58.

[11] S. Saito, T. Wachi, S. Handa, Mater. Sci. Eng. A 161 (1993) 91-96.

[12] S.K. Wu, H.C. Lin, Y.C. Yen, Mater. Sci. Eng. A 215 (1996) 113-119.

[13] S. Miyazaki, Y. Igo, K. Otsuka, Acta Metall. 34 (1986) 2045-2051.

[14] T. Tadaki, Y. Nakata, K. Shimizu, Mater. Trans., JIM 28 (1987) 883-890.

[15] T. Todoroki, H. Tamura, Mater. Trans., JIM 28 (1987) 83-94.

[16] Y. Okamoto, H. Hamanaka, F. Miura, H. Tamura, H. Horikawa, Scripta. Metall. 22 (1988) 517-520.
[17] S.K. Wu, H.C. Lin, Scr. Metall. Mater. 25 (1991) 1295-1298.

[18] M. Nishida, C.M. Wayman, Scr. Metall. 18 (1984) 13891394.

[19] S.K. Wu, H.C. Lin, T.S. Chou, Acta Metall. Mater. 38 (1990) 95-102.

[20] C.M. Hwang, M. Meichle, M.B. Salamon, C.M. Wayman, Philos. Mag., 47A (1983) 9-62, 177-191.

[21] Z. Nishiyama, Martensitic Transformation, Academic Press, New York, 1978, Chap. 3.

[22] A.I. Lotkov, A.V. Kuznetsov, V.N. Griskov, A.A. Botaki, in: Y. Chu, T.Y. Hsu, T. Ko (Eds.), Proc. Int. Symp. on Shape Memory Alloys, Guilin, China, 1986, pp. 153-158.

[23] T. Fukuda, A. Deguchi, T. Kakeshita, T. Saburi, Mater. Trans., JIM 38 (1997) 1057-1062.

[24] H.C. Lin, S.K. Wu, T.S. Chou, H.P. Kao, Acta Metall. Mater. 39 (1991) 2069-2080.

[25] H.C. Lin, S.K. Wu, Metall. Trans. 24A (1993) 293-299.

[26] S.K. Wu, H.C. Lin, Scr. Metall. Mater. 25 (1991) 1529-1532. 